\title{
A Different Flow Field Design Approach for Performance Improvement of a PEMFC
}

\author{
H. Kahraman ${ }^{a}{ }^{*}$, C. HaşimoĞLU ${ }^{a}$, İ. Cevik ${ }^{a}$ And A. MUrCaK ${ }^{b}$ \\ ${ }^{a}$ Sakarya University, Technology Faculty, Mechanical Engineering, 54187 Sakarya \\ ${ }^{b}$ Sakarya University, Institute of Natural and Applied Science, Department of Mechanical Education, \\ 54187 Esentepe, Sakarya, Turkey
}

\begin{abstract}
Flow fields influence the deployment of the reactant gases over the surface of catalyst layer and the removal of the produced water from the cell. An optimum flow field design should provide lowest energy loss, uniform mass distribution and minimize pressure drop between inlet and outlet of the gas stream. An even reactant distribution reduces the mass transport losses and thus allows higher power density. This study is focused on flow fields inspired by veins of the tree leaves, which have effective performance improvement by minimizing the pressure drop and even deploy reactant gases without water flooding. The branching of flow channels corresponds to the Murray's law, which is also applicable to plants. Additionally semi cylindrical obstacles were fabricated at the bottom of the daughter channels to increase the diffusion into the gas diffusion layer. Cylindrical obstacles were applied to reduce the concentration losses, especially at the high current densities. Cell performance and current density vs temperature distribution measurements show that the new innovative designs shows a better performance compared to standard serpentine design by $42.1 \%$ at $0.4 \mathrm{~V}$ operating voltage. Furthermore, homogenous current and temperature distributions and better water removal are achieved.
\end{abstract}

DOI: 10.12693/APhysPolA.131.484

PACS/topics: 88.30.Nn

\section{Introduction}

Fuel cells are a developing energy technology, which offers major advantages and wide range of applications for mobile, transportation and stationary systems [1]. These advantages include high energy efficiency, quiet operation without vibration, portability and almost zero emissions [2]. Fuel cells are electrochemical energy conversion devices that convert chemical energy of a fuel directly into electrical energy $[3,4]$. The polymer electrolyte membrane fuel cell (PEMFC) is considered to be one of the most promising candidates for different applications [5].

The flow-field design in the bipolar plates affects the performance of PEMFC. Flow field design is very important and changing the design can cause differences in peak power density of $300 \%$ between equivalent systems [6]. The main goals of flow-field design are to increase uniformity of the current, temperature distributions and water management at the operating conditions of interest, while maintaining or improving polarization [7].

Understanding and improving liquid water transport throughout the cell has critical importance in PEMFC performance, since flooding has been identified as one of the main current-limiting processes. The ionic conductivity will decrease, if the cell membrane is too dry. On the other hand, presence of flooding in the porous catalyst layer or in the gas diffusion layer (GDL) affects the per-

*corresponding author; e-mail: huseyink@sakarya.edu.tr formance of PEM fuel cell in negative manner, leading to a high concentration potential loss [8]. Local flooding, which might be caused by poor or nonhomogeneous reactant distribution is a crucial issue that should be taken into account, since it usually leads to non-uniform current density and localized hot spots in the membrane [9]. On the other hand, uniform distribution of gases enables uniform current density distribution, which also enables uniform temperature distribution and limited condensation of liquid water. Furthermore, lower mechanical stresses on the membrane electrode assembly (MEA) are observed with effective water management [10-14] and homogeneous reactant distribution [15-18].

The aim of this study is to achieve a better transport with the cylindrical obstacles and a more homogeneous molar spreading of species along the bionic flow channels, thus allowing higher voltage and power density output at different current densities.

\section{Materials and equipment}

The bipolar plates used in this experiment were roughly $3 \mathrm{~mm}$ thick and were machined with $1 \mathrm{~mm}$ diameter carbide end mills. Before the channel machining, both sides of the graphite plate surfaces were machined over by only $0.2 \mathrm{~mm}$ with a large tool. This process provides homogeneous compression over the MEA/GDL and helps to avoid gas leakage. The end plates made of aluminum and $300 \mu \mathrm{m}$ thick gold plated copper plates were used as current collectors.

The graphite plates were grooved with flow field patterns. Grooved channels had depth of $1 \mathrm{~mm}$ and also $1 \mathrm{~mm}$ width. Semi cylindrical obstacles, machined into the flow channel had different dimensions and frequency (Fig. 1). 


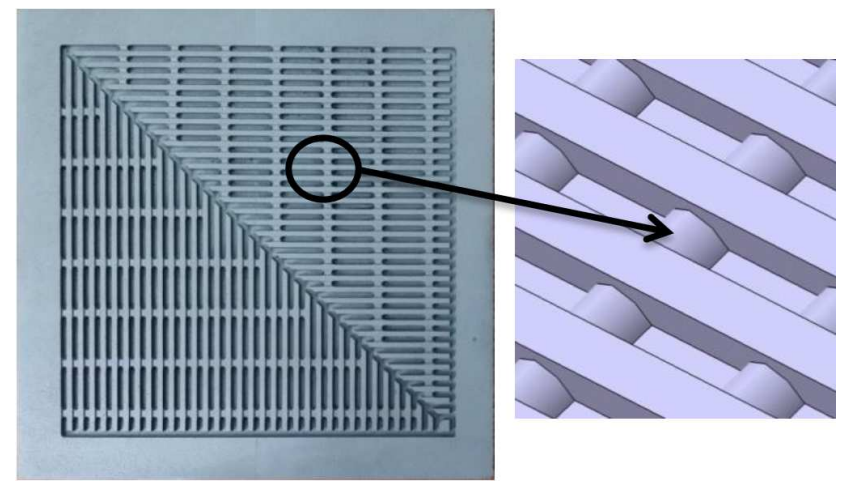

Fig. 1. Nature-inspired design with semi cylindrical obstacles.

\section{Experimental setup}

In this study a single PEM fuel cell with active surface area of $50 \mathrm{~cm}^{2}$ was used for all experiments. The MEA consists of Nafion ${ }^{\circledR}$ HP membrane. Anode and cathode electrodes include 0.4 and $0.2 \mathrm{mg} / \mathrm{cm}^{2}$ platinum load on carbon support, respectively. The AvCarb EP40 GDLs were used in all experiments and had $200 \mu \mathrm{m}$ thickness. The experimental setup shown in Fig. 2, consists of primary components, i.e., SLB-2014 electronic load, two Aalborg DFC-26S-VAL5-C2 mass flow controllers, two humidity bottles, two heated/insulated gas lines, temperature controllers, two pressure regulators, $\mathrm{H}_{2}-\mathrm{O}_{2}$ tubes. Backpressures are controlled by backpressure regulators. The fuel cell polarization curves are obtained by measuring the current values at different voltages, controlled by the electronic load bank. System includes a computerbased control and data acquisition system, based on a LabVIEW. The mass flow rates are set manually and read through the LCD display. The $\mathrm{H}_{2}$ flow rate was $0.168 \mathrm{l} / \mathrm{min}$ and the $\mathrm{O}_{2}$ flow rate was $0.28 \mathrm{l} / \mathrm{min}$. Thus the stoichiometry of 1.2 and 2 for $\mathrm{H}_{2}$ and $\mathrm{O}_{2}$, respectively, was controlled. The stoichiometric rate is estimated for the maximum current value and was fixed during the tests. Cell temperature was kept at $60^{\circ} \mathrm{C}$ during all fuel cell experiments. The cell temperature was measured by thermocouples installed within the end plates. The tem-

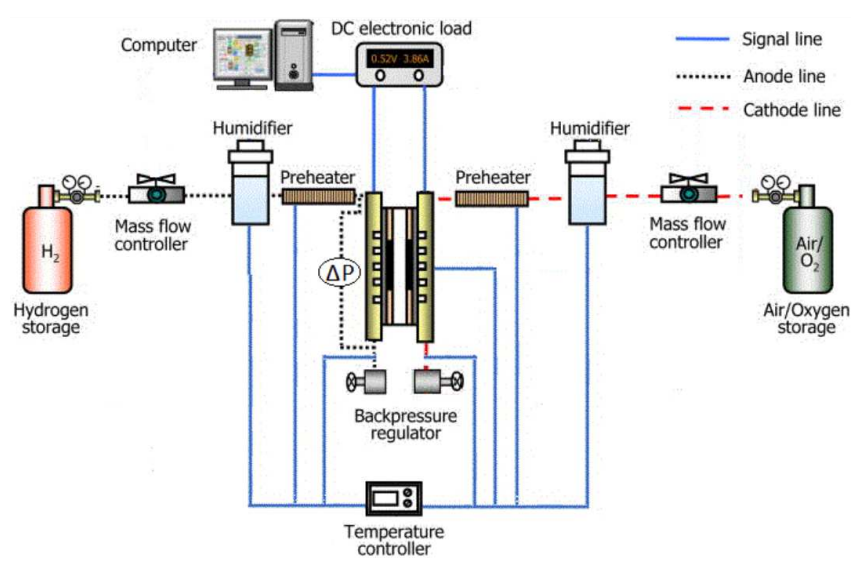

Fig. 2. Experimental setup. peratures of the oxidant and fuel were at $46^{\circ} \mathrm{C}, 54^{\circ} \mathrm{C}$, and $60^{\circ} \mathrm{C}$, in order to observe humidification conditions with respect to cell temperature of $60^{\circ} \mathrm{C}$. These conditions correspond to relative humidity of the inlet streams of $50 \%, 75 \%$, and $100 \%$ respectively. Reactant gases are humidified by humidification system produced by Fuel Cell Technologies, Inc. The system includes dual temperature controller, including output gas line heaters, on/off bypass valves, sight glass for each humidity bottle. Nafion tubing was inserted into the bottle to provide dew-point humidity level for the gas passing through the tubing. Regulation of the water temperature controls the humidification of the reactant gases. The higher the water temperature the higher is the gas humidification. The overall cell temperature was measured by thermocouples installed within the end plates and was controlled by heaters in contact with the end plates. The heaters and thermocouples were also connected to a temperature control system.

While testing the voltage and power as function of current density, polarization curve for a $50 \mathrm{~cm}^{2}$ single cell, US Fuel Cell Council, Single Cell Test Protocol was taken, as reference. Before all tests, cell has been kept at open circuit voltage (OCV) for 15 minutes, than a fixed current of $10 \mathrm{~A}$ has been applied for 30 minutes, to ensure that the fuel cell had reached a stable operating condition. For investigation of the water removal capability of the channel designs, fixed current tests were implemented at 10, 20,30 and $40 \mathrm{~A}$ for 5 minutes. Voltage drop behavior of the samples was observed.

\section{Results and discussion}

Two different channel configurations have been used in the experiments. Figure 3 shows $I-V$ curves of the PEM fuel cells with different bipolar plate flow field configurations at $60^{\circ} \mathrm{C}$ cell temperature, 1.5 bar back pressure and $100 \%$ relative humidity of both anode and cathode sides. The channel configuration with semi cylindrical obstacles inside the flow channels shows a better performance than the obstacle-free ones, especially in the higher current density regions. This behavior can be attributed to the presence of semi cylindrical obstacles. These obstacles have improved the water removal capability of the

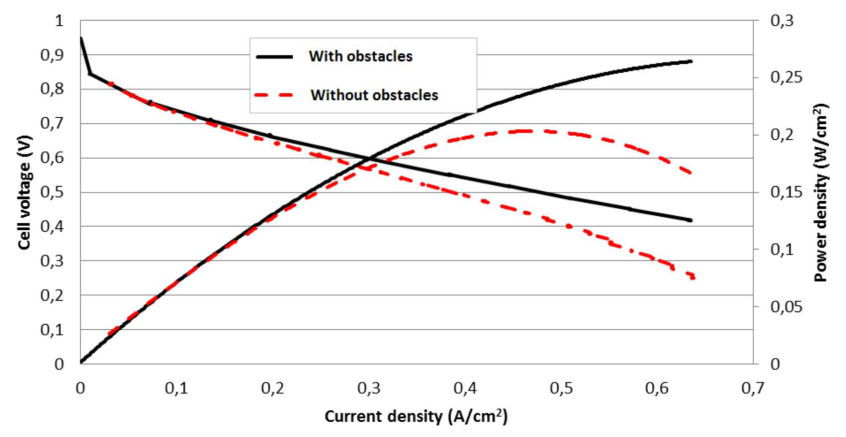

Fig. 3. Polarization and power density curves with and without obstacles in the flow channels. 
channels by transporting the reactant gases through the GDL. Furthermore, due to the tapered section, reactants velocity is increasing at the obstacle sides. This increased velocity gives an effect of spraying the water droplets towards the outlet. Water removal effect of the obstacles can be observed at the high current density regions in Fig. 3. Due to usage of pure $\mathrm{O}_{2}$ at the cathode, a prominent drop was not observed in the $I-V$ and $I-P$ curves in high current density region.

The current distribution in PEMFC is not uniform. This non-uniformity can cause performance drop, the starvation process within a fuel cell and the membrane degradation which lead to a reduced lifetime of the PEMFCs. Water accumulation along flow-field can also cause the non-uniformity of current distribution and it is a major problem in maintaining high performance in the PEMFCs. The flow fields machined on bipolar plate distribute reactants and remove the produced water from the fuel cells. Reactant distribution greatly influences the performance of fuel cells, especially the concentration losses. Current and temperature distribution measurements are an indicator of the local electrochemical reaction conditions.

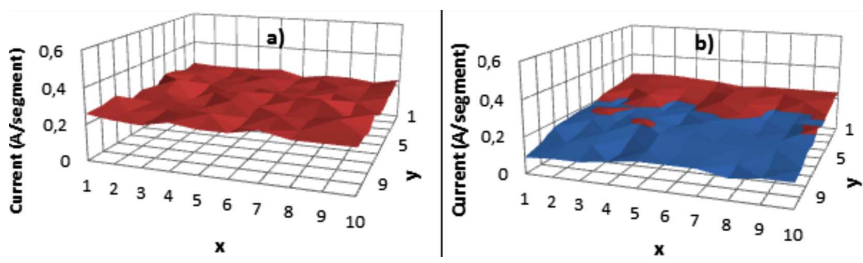

Fig. 4. Comparison of measured current distribution inside PEMFC (a) with obstacles and (b) without obstacles.

Figure 4 shows the current distributions. Figures $4 \mathrm{a}$ and $\mathrm{b}$ represent the current density distributions over the surface of the electrodes with and without obstacles inside the flow channels, respectively. The flow field with obstacles inside the channels shows almost homogeneous current distribution (Fig. 4a) relative to (Fig. 4b). Inlet $(0,10)$ and outlet $(10,0)$ regions have approximately the same current values. This means the pressure drop between inlet and outlet is negligible. Due to the great impact of obstacles on water removal and on reactant distribution, this design can be assumed as a promising candidate for flow field design for PEMFCs.

\section{Conclusions}

The performance curves of two samples show that the obstacles inside the flow channels improve the fuel cell performance. Design of channels with obstacles has performed better than the obstacle-free one, with higher maximum power density by about $10-15 \%$. This is due to the better mass transport and water removal capability of the obstacles inside the channels.
The second advantage of the obstacles can be seen in current distribution. The obstacles inside the flow fields give a positive effect to mass transport which is very important to fuel cells, especially at high current densities, where performance can be limited by mass transport issues.

\section{References}

[1] A. Kopanidis, A. Theodorakakos, M. Gavaises, D. Bouris, Int. J. Thermal Sci. 50, 456 (2011).

[2] O.Z. Sharaf, M.F. Orhan, Renew. Sust. Energ. Rev. 32, 810 (2014).

[3] M. Grujicic, K.M. Chittajallu, Chem. Eng. Sci. 59, $5883(2004)$.

[4] X.D. Wang, Y.Y. Duan, W.M. Yan, X.F. Peng, Electrochim. Acta 53, 5334 (2008).

[5] A. Aiyejina, M.K.S. Sastry, J. Fuel Cell Sci. Tech. 9, 011011 (2012).

[6] D. Spernjak, A.K. Prasad, S.G. Advani, J. Power Sources 195, 3553 (2010).

[7] S. Shimpalee, S. Greenway, J.W. Van Zee, J. Power Sources 160, 398 (2006).

[8] N. Bunmark, S. Limtrakul, M.W. Fowler, T. Vatanatham, J. Gostick, Int. J. Hydrogen Energ. 35, 6887 (2010).

[9] P. Quan, M.C. Lai, J. Power Sources 164, 222 (2007).

[10] P.M. Belchor, M. Madalena, C. Forte, D.E.O.S Carpenter, Int. J. Hydrogen Energ. 37, 11904 (2012).

[11] A. Su, F.B. Weng, C.Y. Hsu, Y.M. Chen, Int. J. Hydrogen Energy, 31, 1031 (2006).

[12] N. Akhtar, A. Qureshi, J. Scholta, C. Hartnig, M. Messerschmidt, W. Lehnert, Int. J. Hydrogen Energy 34, 3104 (2009).

[13] X. Liu, H. Guo, F. Ye, C. Ma, Int. J. Hydrogen Energy 33, 1040 (2008).

[14] P.V. Suresh, S. Jayanti, Int. J. Hydrogen Energy 35, $6872(2010)$.

[15] Y.S. Chen, H. Peng, J. Power Sources, 196, 1992 (2011).

[16] J. Lobato, P. Canizares, M.A. Rodrigo, F.J. Pinar, D. Ubeda, J. Power Sources 196, 4209 (2011).

[17] L. Peng, J. Mai, P. Hu, X. Lai, Z. Lin, Renew. Energy 36, 1413 (2011).

[18] D. Úbeda, P. Cańizares, M.A. Rodrigo, F.J. Pinar, J. Lobato, Int. J. Hydrogen Energ. 39, 21678 (2014). 